\title{
Homer2 Is Necessary for EtOH-Induced Neuroplasticity
}

\author{
Karen K. Szumlinski, ${ }^{1}$ Kevin D. Lominac, ${ }^{1}$ Erik B. Oleson, ${ }^{1}$ Jennifer K. Walker, ${ }^{1}$ Ashley Mason, ${ }^{1}$ Marlin H. Dehoff, ${ }^{3}$ \\ Matthias Klugman, ${ }^{4}$ Stephanie Cagle, ${ }^{1}$ Kristine Welt, ${ }^{1}$ Matthew During, ${ }^{5}$ Paul F. Worley, ${ }^{3}$ Lawrence D. Middaugh, ${ }^{1,2}$ and \\ Peter W. Kalivas ${ }^{1}$ \\ ${ }^{1}$ Department of Neurosciences and ${ }^{2}$ Department of Psychiatry and Behavioral Science and Charleston Alcohol Research Center, Medical University of South \\ Carolina, Charleston, South Carolina 29425, 32Department of Neuroscience, The Johns Hopkins University School of Medicine, Baltimore, Maryland 21205, \\ ${ }^{4}$ Interdisciplinary Center for Neurosciences, University of Heidelberg, 69123 Heidelberg, Germany, and ${ }^{5}$ Department of Molecular Medicine and Pathology, \\ University of Auckland, Auckland 1003, New Zealand
}

Homer proteins are integral to the assembly of proteins regulating glutamate signaling and synaptic plasticity. Constitutive Homer2 gene deletion [knock-out (KO)] and rescue with adeno-associated viral (AAV) transfection of Homer2b was used to demonstrate the importance of Homer proteins in neuroplasticity produced by repeated ethanol (EtOH) administration. Homer $2 \mathrm{KO}$ mice avoided drinking high concentrations of $\mathrm{EtOH}$ and did not develop place preference or locomotor sensitization after repeated EtOH administration. The deficient behavioral plasticity to EtOH after Homer2 deletion was paralleled by a lack of augmentation in the rise in extracellular dopamine and glutamate elicited by repeated $\mathrm{EtOH}$ injections. The genotypic differences in EtOH-induced change in behavior and neurochemistry were essentially reversed by AAV-mediated transfection of Homer $2 b$ into accumbens cells including, differences in EtOH preference, locomotor sensitization, and $\mathrm{EtOH}$-induced elevations in extracellular glutamate and dopamine. These data demonstrate a necessary and active role for accumbens Homer2 expression in regulating EtOH-induced behavioral and cellular neuroplasticity.

Key words: Homer proteins; EtOH; NMDA receptor; neuroplasticity; glutamate; dopamine

\section{Introduction}

Ethanol (EtOH) is a drug of abuse that inhibits glutamate receptor function and affects neurotransmission within the mesocorticolimbic circuitry implicated in drug and natural reward, including the nucleus accumbens (Koob et al., 1998; Woodward, 2000; Gonzales et al., 2004). Many of the acute behavioral effects of $\mathrm{EtOH}$ are related to the inhibition of glutamate receptor signaling (Woodward, 2000), and enduring adaptations in glutamate receptor signaling are implicated in the development of $\mathrm{EtOH}$ dependence, tolerance, and addiction (Chandler, 2003; Krystal et al., 2003). Thus, proteins regulating glutamatergic synaptic function are hypothesized to gate the development of EtOH-induced behavioral plasticity (Chandler, 2003).

The Homer family of proteins modulate glutamate signaling in the postsynaptic density (PSD) and are candidate regulators of EtOH-induced plasticity. Homers are encoded by three genes (Homer1-Homer3) that provide constitutive isoforms (Homer1b/c/d, Homer2a/b, and Homer3) and immediate early gene products (Homerla and ania-3) (Xiao et al., 2000; de Bar-

Received April 19, 2005; revised May 24, 2005; accepted June 12, 2005.

This work was supported by National Institute on Drug Abuse Grants DA-11742 (P.F.W.) and DA-03906 and DA-14185 (P.W.K.), and National Institute on Alcohol Abuse and Alcoholism Grants P50-AA1076 (L.D.M., P.W.K.; Charleston Alcohol Research Center) and AA-013517 (K.K.S.; Integrative Neuroscience Initiative on Alcoholism West Pilot Project). We thank Axaron AGY (Heidelberg, Germany) for assistance in generating the Homer2 knock-out mice, and G. Harris (Johns Hopkins University School of Medicine) and Joseph Vallone (Medical University of South Carolina) for genotyping and maintenance of the mouse colonies.

Correspondence should be addressed to Dr. Karen K. Szumlinski, Department of Psychology, University of California Santa Barbara, Santa Barbara, CA 93106-9660. E-mail: szumlinski@psych.ucsb.edu.

DOI:10.1523/JNEUROSCI.1529-05.2005

Copyright $\odot 2005$ Society for Neuroscience $\quad$ 0270-6474/05/257054-08\$15.00/0 tolomeis and Iasevoli, 2003). Homer proteins interact via an Ena/ VASP1 (for vasodilator-stimulated phosphoprotein) (EVH1) homology domain with a proline-rich motif located on a number of proteins, including group 1 metabotropic glutamate receptors (mGluR1/5), inositol-1,4,5-triphosphate receptors, TRP (for transient receptor potential) cation channels, and the NMDA receptor-associated scaffolding protein Shank (Xiao et al., 2000; de Bartolomeis and Iasevoli, 2003; Rong et al., 2003; Yuan et al., 2003). In contrast to the truncated immediate early gene isoforms, constitutive Homer isoforms contain a leucine zipper motif and a coiled-coil domain at the $\mathrm{N}$ terminus, which enables multimerization and cross-linking between mGluR1/5 and EVH1-bound partners (Tu et al., 1999). Thus, constitutive Homer proteins are integral to synaptic architecture and promote efficient glutamate receptor signaling complexes (Xiao et al., 2000; Sala et al., 2003; Shiraishi et al., 2003).

In vivo evidence indicates a necessary and active role for constitutive Homer protein expression in the nucleus accumbens for the maintenance and regulation of extracellular levels of glutamate relevant to addiction. Mice with null mutations of either Homer1 or Homer2 exhibit abnormalities in accumbens extracellular glutamate that are similar to those observed in animals withdrawn from repeated cocaine treatment (Szumlinski et al., 2004). The glutamatergic abnormalities of Homer mutant mice accompany a "presensitized" behavioral phenotype characterized by heightened sensitivity to cocaine reward and psychomotor activation (Szumlinski et al., 2004). Although Homerl deletion produced learning deficits that confounded the interpretation of Homer1 role in reward (Szumlinski et al., 2004, 2005), the phe- 
notype of Homer2 knock-out (KO) mice appears to be selective for alterations in cocaine reward (Szumlinski et al., 2004).

Given the effects of Homer gene deletions on glutamate transmission and the fact that EtOH modulates glutamate receptors and transmission (Chandler, 2003; Krystal et al., 2003), the present study investigated the interactions between Homer2 and EtOH. Mice sustaining a constitutive deletion of the Homer 2 gene $(\mathrm{KO})$ were administered acute or repeated $\mathrm{EtOH}$, and effects on EtOH-induced behaviors and nucleus accumbens dopamine and glutamate transmission were quantified. In addition, reversal of observed genotypic differences by an adeno-associated viral (AAV) transfection of nucleus accumbens cells was also performed. The results of this study indicate that Homer2 in the accumbens regulates sensitivity to acute $\mathrm{EtOH}$ administration and is necessary for EtOH-induced behavioral and neurochemical plasticity.

\section{Materials and Methods}

Subjects. Mice with null mutations of Homer2 and their wild-type (WT) mice $(\mathrm{F} 10-\mathrm{F} 12$; C57BL/6J $\times 129 \mathrm{Xi} / \mathrm{SvJ})$ were generated and maintained by heterozygous mating as described previously (Szumlinski et al., 2004). Because insufficient numbers of male mice were available at the time of study, both adult ( $8-10$ weeks of age at the start of experimentation) male and female mice were used. The numbers of male and female mice within each treatment group were approximately equal \pm 1 . Mice were housed individually under standard conditions as described previously (Szumlinski et al., 2004).

$\mathrm{EtOH}$ and saccharin preference. EtOH consumption and preference was assessed using a two-bottle choice procedure similar to that described previously for C57BL/6J (B6) mice (Nocjar et al., 1999). Briefly, mice were presented with two identical $50 \mathrm{ml}$ sipper tubes in the home cage for a period of $24 \mathrm{~h}$. One tube contained tap water and the other tube contained increasing concentrations of $\mathrm{EtOH}(0,3,6$, and 12\% v/v). Bottles were presented with each EtOH concentration for $4 \mathrm{~d}$, and the volume consumed was calculated daily based on sipper tube weight before and after presentation. The mean volume consumed over the $4 \mathrm{~d}$ was used in the statistical analysis. For comparison, saccharin preference was assessed after $4 \mathrm{~d}$ presentation of a $0.9 \%(\mathrm{w} / \mathrm{v})$ saccharin solution versus water. To control for spillage and evaporation, the weights of bottles on two dummy cages were recorded throughout testing, and the average volume lost attributable to bottle handling/evaporation was subtracted from the daily record for each animal.

Place conditioning and motor activity. To assess EtOH conditioned reward and locomotor activity, a biased place conditioning apparatus was used in a manner identical to previous reports for Homerl and Homer2 KO mice (Szumlinski et al., 2004). The procedures to induce EtOH place conditioning were similar to that described for C57BL/6J mice (Nocjar et al., 1999). In brief, place conditioning to EtOH was produced by eight repeated pairings, on alternating days, of intraperitoneal injections of $0,1,2$, or $3 \mathrm{~g} / \mathrm{kg}$ EtOH with the nonpreferred compartment and water vehicle (volume of $0.02 \mathrm{ml} / \mathrm{g}$ body weight) with the preferred compartment of the place conditioning apparatus. Control groups received water vehicle in both compartments. A postconditioning test followed the last $\mathrm{EtOH} /$ water conditioning session, using identical procedures as those used on the preconditioning test. Both the conditioning and test sessions were a total of $15 \mathrm{~min}$ in duration. EtOH-induced changes in locomotor behavior were detected by two photocell beams and recorded on each EtOH conditioning day. The amount of conditioning was expressed as the difference in the amount of time spent in the nonpreferred, EtOH-paired compartment on the preconditioning versus postconditioning tests (occupancy difference in seconds).

EtOH-induced sedation. To assess the motor-impairing effects of higher EtOH doses, Homer2 $\mathrm{KO}$ and their WT mice were injected intraperitoneally with $5 \mathrm{~g} / \mathrm{kg} \mathrm{EtOH}$, and the time to regain their righting reflex was determined. Mice were placed in clear Plexiglas chambers, injected with $\mathrm{EtOH}$, and, once immobile ( $\sim 2-3 \mathrm{~min})$, placed onto their backs for the duration of the study. The time taken to place all four paws on the floor of the chamber was determined by behavioral observation using a stopwatch.

Blood EtOH concentration. To assess for genotypic differences in EtOH metabolism and the development of metabolic tolerance, WT and Homer2 $\mathrm{KO}$ mice received eight intraperitoneal injections of $3.0 \mathrm{~g} / \mathrm{kg} \mathrm{EtOH}$ every other day, as per the place conditioning study. Blood was sampled from the infraorbital sinus at 5, 15, and $30 \mathrm{~min}$ after the $\mathrm{EtOH}$ injections 1 and 8 . Blood EtOH levels (BEL) (milligrams percent) were determined using gas chromatography as described previously for C57BL/6 mice (Middaugh et al., 1992).

Surgery, in vivo microdialysis, dopamine, and glutamate concentrations. In vivo microdialysis procedures were performed on injection 1 of repeated EtOH administration ( $3 \mathrm{~g} / \mathrm{kg}$, i.p.; volume of $0.02 \mathrm{ml} / \mathrm{kg}$ ) and then on injection 8 using the contralateral side of the head. The surgical and in vivo microdialysis procedures were similar to those described previously (Szumlinski et al., 2004). Dialysate was collected in 20 min fractions for $1 \mathrm{~h}$ before $\mathrm{EtOH}$ injection and $3 \mathrm{~h}$ thereafter. Consistent with the injection regimen used in the place conditioning study, injections 2-7 were administered every other day to mice in their home cages. Samples were assayed by HPLC with electrochemical detection for dopamine or with fluorescent detection for glutamate as described previously (Szumlinski et al., 2004). After the second microdialysis session, mice were killed, and their brains were removed and stained with cresyl violet for histological examination.

Intra-accumbens NMDA receptor blockade and locomotor activity. Sensitivity to EtOH is associated with sensitivity to the behavioral effects of NMDA receptor antagonists (Krystal et al., 2003). Thus, to assess for genotypic differences in sensitivity to the effects of accumbens NMDA receptor blockade, WT and Homer2 $\mathrm{KO}$ mice were fitted bilaterally with indwelling guide cannulas (24 gauge) aimed at the nucleus accumbens. After 7-10 d recovery, a series of locomotor activity tests were conducted using a within-subjects design. For these tests, mice were infused with one of three concentrations of the competitive NMDA receptor antagonist 3-(2-carboxypiperazin-4-yl)propyl-1-phosphonic acid (CPP), and locomotor activity was assessed for $2 \mathrm{~h}$. Testing occurred every 3-4 d, and the order of dosing was counterbalanced within each genotype across the test days.

Behavioral and neurochemical studies after AAV infusion in WT and KO mice. AAVs carrying the Homer $2 b$ splice variant or enhanced green fluorescent protein (GFP) were generated and infused as described previously (Szumlinski et al., 2004). Three weeks after AAV infusion, Homer2 WT and KO animals were subjected to either a battery of behavioral tests or in vivo microdialysis procedures. For the behavioral battery, animals were first assessed for EtOH place conditioning and EtOH-induced changes in locomotor activity as described above. Because the greatest genotypic difference in behavior was observed at the $3 \mathrm{~g} / \mathrm{kg}$ EtOH dose, this dose was selected for study. Four days after place conditioning, animals were assessed for $\mathrm{EtOH}$ preference and consumption in a fourbottle choice test $(0,3,6$, vs $12 \% \mathrm{v} / \mathrm{v})$ under $24 \mathrm{~h}$ access conditions in the home cage in a manner similar to that described in rats (Backstrom et al., 2004). Bottles were presented every weekday for a period of 2 weeks, and the average preference for each concentration and $\mathrm{EtOH}$ intake during the second week was used in the statistical analysis. For in vivo microdialysis, the procedures were identical to those described above. To verify viral transfection, immunohistochemistry for hemagglutinin (HA)tagged Homer2 was conducted on $4 \%$ paraformaldehyde-fixed accumbens tissue slices (50 $\mu \mathrm{m}$ thick) using standard procedures (primary anti-HA antibody at 1:1000, and secondary antibody at 1:2000, followed by light microscopy).

EtOH preference and consumption after AAV infusion in B6 mice. To ascertain whether or not AAV-Homer2b infusion would influence EtOH reward in a mouse strain that exhibits high EtOH preference and consumption, adult male C57BL/6J mice (25-30 g) were obtained from The Jackson Laboratory (Bar Harbor, ME). Mice were surgically implanted with guide cannulas and infused intra-accumbens with either AAV-GFP or AAV-Homer $2 b$ in a manner identical to that described above. Three weeks after infusion, mice were tested for $\mathrm{EtOH}$ preference and consumption using a two-bottle choice procedure in a manner similar to that described for nontransfected WT and KO mice (average across $4 \mathrm{~d}$ of 
A

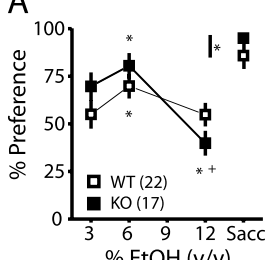

B

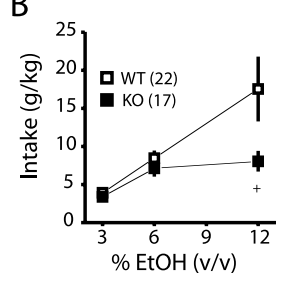

C

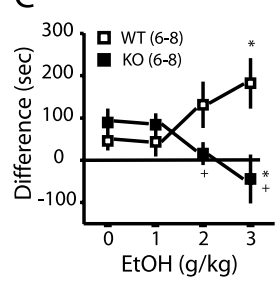

Figure 1. Homer2 $\mathrm{KO}$ mice exhibit aversion to EtOH. $\boldsymbol{A}$, When assessed in a two-bottle choice task, $\mathrm{KO}$ mice exhibited aversion to $12 \% \mathrm{EtOH}(\mathrm{EtOH})(\mathrm{v} / \mathrm{v})$ (genotype $\times$ dose interaction, $\left.F_{(3,111)}=5.72 ; p=0.0004\right)$ but did not differ from WT in their preference for lower EtOH concentrations or for a $0.9 \%$ saccharin (Sacc) solution ( $p>0.05$ ). B, KO mice exhibited reduced EtOH intake at $12 \%$ EtOH solution (genotype $\times$ dose interaction, $F_{(3,111)}=2.67 ; p=0.05$ ). , The repeated pairing of EtOH ( 8 injections at $0,1,2$, or $3 \mathrm{~g} / \mathrm{kg}$, i.p.) with a distinct environment induced place conditioning in WT mice but induced place aversion in $\mathrm{KO}$ animals (genotype $\mathrm{X}$ dose interaction, $\left.F_{(3,55)}=5.52 ; p=0.004\right)$. Data are shown as mean $\pm \mathrm{SEM}$, and the number of animals used is in parentheses. ${ }^{*} p<0.05$ versus $0 \%$ or $0 \mathrm{~g} / \mathrm{kg} \mathrm{EtOH} ;{ }^{+} p<0.05$ versus WT.

presentation), with the exception that a higher concentration $(18 \% \mathrm{v} / \mathrm{v})$ was also assessed. AAV transfection was verified as described above.

Immunoblotting for glutamate receptors. Accumbens tissue was subjected to differential centrifugation to obtain the plasma membrane subcellular fraction as described previously (Toda et al., 2003). Immunoblotting for the NR2a and NR2b subunits of the NMDA receptor as well as that for mGluR5 was performed as described previously for total tissue content in Homer $2 \mathrm{KO}$ mice (Szumlinski et al., 2004). Immunoblots were quantified using NIH Image 1.62 and were normalized to percentage of WT values.

Statistical analysis. Data were evaluated using two-way or three-way ANOVAs and, in the case of the four-bottle choice and microdialysis studies, with repeated measures over concentration or time. Comparisons between two populations were made using a Student's $t$ test. Post hoc comparisons were made using a least significant difference (LSD) test.

\section{Results}

\section{Homer2 deletion increased the aversive properties of higher EtOH concentrations}

EtOH preference and consumption were examined using a $24 \mathrm{~h}$ ad libitum access, two-bottle choice procedure ( 0 vs 3,6 , or $12 \%$ $\mathrm{EtOH}, \mathrm{v} / \mathrm{v}$ ) and revealed genotypic differences at the highest $\mathrm{EtOH}$ concentration tested. Both WT and KO mice showed a biphasic $\mathrm{EtOH}$ preference curve with significant preference over water at $6 \%$ but not at 3 or $12 \% \mathrm{EtOH}$.

However, at $12 \% \mathrm{EtOH}$, the Homer $2 \mathrm{KO}$ mice drank preferentially from the bottle containing water (Fig. $1 \mathrm{~A}$ ), and their total $\mathrm{EtOH}$ intake was less than half that of WT mice (WT, $17.52 \pm$ $4.21 \mathrm{~g} / \mathrm{kg} ; \mathrm{KO}, 8.06 \pm 1.33 \mathrm{~g} / \mathrm{kg} ; p>0.05$ ) (Fig. $1 B$ ). No genotypic differences were observed for $\mathrm{EtOH}$ preference or consumption at lower EtOH concentrations, nor were significant genotypic differences observed for the average volume of water consumed during testing (WT, $7.56 \pm 1.44 \mathrm{ml}$ KO, $8.37 \pm 1.18 \mathrm{ml} ; p>$ $0.05)$ or for their preference for a palatable $0.9 \%(\mathrm{w} / \mathrm{v})$ saccharin solution (Fig. $1 \mathrm{~A}$, right).

The genotypic differences in EtOH consumption were paralleled by EtOH-induced place conditioning. Repeated pairings of $\mathrm{EtOH}(0-3 \mathrm{~g} / \mathrm{kg}$, i.p., for eight injections) with a distinct environment resulted in a dose-dependent increase in the time spent in the EtOH-paired compartment in WT mice. In contrast, repeated $\mathrm{EtOH}$ administration produced a dose-dependent decrease in the time spent in the EtOH-paired compartment in $\mathrm{KO}$ animals. In fact, when compared with $0 \mathrm{~g} / \mathrm{kg}$ controls, $\mathrm{KO}$ mice injected repeatedly with $3 \mathrm{~g} / \mathrm{kg}$ EtOH exhibited place aversion toward the EtOH-paired compartment (Fig. 1C). The genotypic difference in place conditioning was not related to differences in
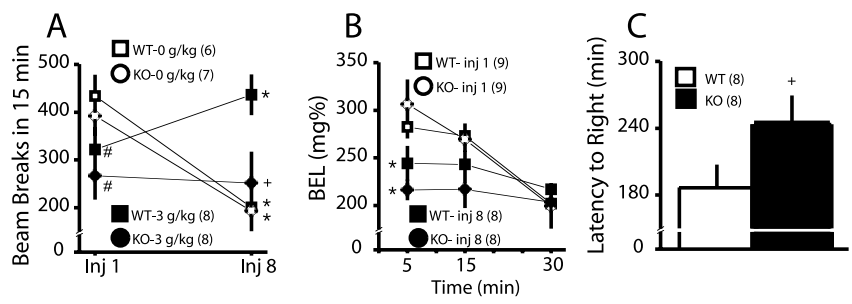

Figure 2. Homer2 $\mathrm{KO}$ mice do not exhibit behavioral adaptation to repeated EtOH administration. $A$, Both genotypes exhibited locomotor inhibition during an acute injection of $3 \mathrm{~g} / \mathrm{kg}$ $\mathrm{EtOH}(\mathrm{EtOH})$ and adaptation to daily saline injections; however, only WT mice exhibited an increase in EtOH-induced locomotion after repeated administration of $3 \mathrm{~g} / \mathrm{kg} \mathrm{EtOH}$ (dose $\times$ injection, $F_{(1,25)}=8.92, p=0.0002$; genotype $\times$ injection number, $F_{(1,25)}=2.77, p=0.05$ ). $\boldsymbol{B}$, No genotypic differences were measured in $B E L s$ after acute or repeated EtOH administration (genotype $\times$ injection $\times$ time interaction, $F_{(2,58)}=0.87 ; p=0.58$ ), and BEL after repeated EtOH was lower than acute EtOH in both genotypes (injection effect, $F_{(2,29)}=2.99, p=0.07$; injection $\times$ time, $\left.F_{(4,58)}=4.21, p=0.02\right)$. C, Homer2 $\mathrm{KO}$ mice exhibited a longer latency to regain a righting reflex after acute injection with $5 \mathrm{~g} / \mathrm{kg} \mathrm{EtOH}\left(F_{(1,15)}=3.21 ; p=0.04\right)$. Data are shown as mean \pm SEM, and the number of animals is in parentheses. ${ }^{*} p<0.05$ versus injection $1 ;{ }^{+} p<0.05$ versus WT; ${ }^{\#} p<0.05$ versus $0 \mathrm{~g} / \mathrm{kg}$.

the time spent in the nonpreferred compartment before conditioning, because WT and KO mice spent a similar amount of time in the nonpreferred compartment on the pretest session (WT, $121.9 \pm 21.8 \mathrm{~s}$ vs $\mathrm{KO}=133.7 \pm 21.3 \mathrm{~s} ; p>0.05)$. Collectively, the $\mathrm{EtOH}$ consumption and place conditioning data indicate that Homer2 deletion increases the aversive or reduces the rewarding properties of higher EtOH concentrations, without impairing the ability to discriminate between different EtOH concentrations. The blunted $\mathrm{EtOH}$ reward exhibited by Homer $2 \mathrm{KO}$ mice does not appear to be related to an impairment in general reward processes because Homer2 KO mice (1) exhibit enhanced, not blunted, cocaine reward (Szumlinski et al., 2004), (2) did not differ from WT mice regarding water intake and saccharin preference in the present study, and (3) do not differ from WT mice regarding food-induced place conditioning or instrumental responding for sucrose (Szumlinski et al., 2004, 2005).

\section{Homer2 deletion increased sedation and prevented locomotor sensitization by $\mathrm{EtOH}$}

EtOH-induced effects on motor activity were determined by measuring locomotor behavior during the $15 \mathrm{~min}$ EtOH conditioning sessions in the conditioned place preference experiment (Fig. 1C). The motor response to vehicle $(0 \mathrm{~g} / \mathrm{kg})$ controls was equivalent between WT and $\mathrm{KO}$ mice and decreased to an equal extent by the eighth injection (Fig. $2 \mathrm{~A}$ ). Doses of acute EtOH $<3$ $\mathrm{g} / \mathrm{kg}$ did not alter the locomotor behavior of either WT or KO mice (data not shown), and $3 \mathrm{~g} / \mathrm{kg}$ EtOH marginally reduced locomotion to a similar extent in both genotypes. However, whereas WT mice showed locomotor sensitization by the eighth injection of $3 \mathrm{~g} / \mathrm{kg} \mathrm{EtOH}$, the motor response in Homer $2 \mathrm{KO}$ mice was unaltered between the first and eighth injection (Fig. 2A). The genotypic distinction in EtOH-induced motor plasticity did not result from differences in EtOH metabolism because the BELs attained at 5,15 , or 30 min after acute or repeated administration of $3 \mathrm{~g} / \mathrm{kg}$ EtOH did not differ between WT and KO mice, and repeated $\mathrm{EtOH}$ administration reduced the maximum BEL attained in either genotype to a similar extent (Fig. 2B). Thus, both $\mathrm{EtOH}$ metabolism and the development of pharmacokinetic tolerance were equivalent between WT and KO mice.

The sedative actions of EtOH were examined by measuring the time to regain a righting reflex after injecting an anesthetic 
Table 1. Comparison of the basal extracellular levels $( \pm$ SEM) of dopamine and glutamate in the nucleus accumbens of Homer2 WT and K0 mice on injections 1 and 8 of repeated EtOH treatment ( $3 \mathbf{g} / \mathbf{k g}$, i.p.)

\begin{tabular}{|c|c|c|c|c|c|}
\hline \multirow[b]{2}{*}{ Genotype } & \multirow[b]{2}{*}{ AAV } & \multicolumn{2}{|c|}{ Dopamine (fmol/sample) } & \multicolumn{2}{|c|}{ Glutamate (pmol/sample) } \\
\hline & & Injection 1 & Injection 8 & Injection 1 & Injection 8 \\
\hline WT & None & $13.9 \pm 0.9(7)$ & $13.9 \pm 1.1(5)$ & $112.1 \pm 12.5(8)$ & $152.0 \pm 23.4(6)$ \\
\hline \multirow[t]{2}{*}{ KO } & None & $12.2 \pm 0.5(5)$ & $13.6 \pm 0.9(5)$ & $50.6 \pm 4.2(6)^{+}$ & $41.7 \pm 12.9(5)^{+}$ \\
\hline & GFP & $10.1 \pm 1.7(9)$ & $12.3 \pm 1.1(8)$ & $90.6 \pm 10.7(6)$ & $100.8 \pm 12.0(5)$ \\
\hline \multirow[t]{2}{*}{ WT } & Homer $2 \mathrm{~b}$ & $9.5 \pm 3.5(6)$ & $9.4 \pm 1.5(8)$ & $120.4 \pm 23.6(7)$ & $121.9 \pm 18.4(6)$ \\
\hline & GFP & $9.1 \pm 1.2(9)$ & $12.7 \pm 3.6(7)$ & $27.8 \pm 7.2(13)^{+}$ & $40.2 \pm 7.0(9)^{+}$ \\
\hline KO & Homer2b & $8.7 \pm 1.0(7)$ & $8.7 \pm 0.6(10)$ & $51.5 \pm 8.8(11)^{+\#}$ & $80.8 \pm 7.4(5)^{\#}$ \\
\hline
\end{tabular}

Sample sizes are indicated in parentheses. ${ }^{+} p<0.05$ versus WT; ${ }^{\#} p<0.05$ versus AAV-GFP.

A
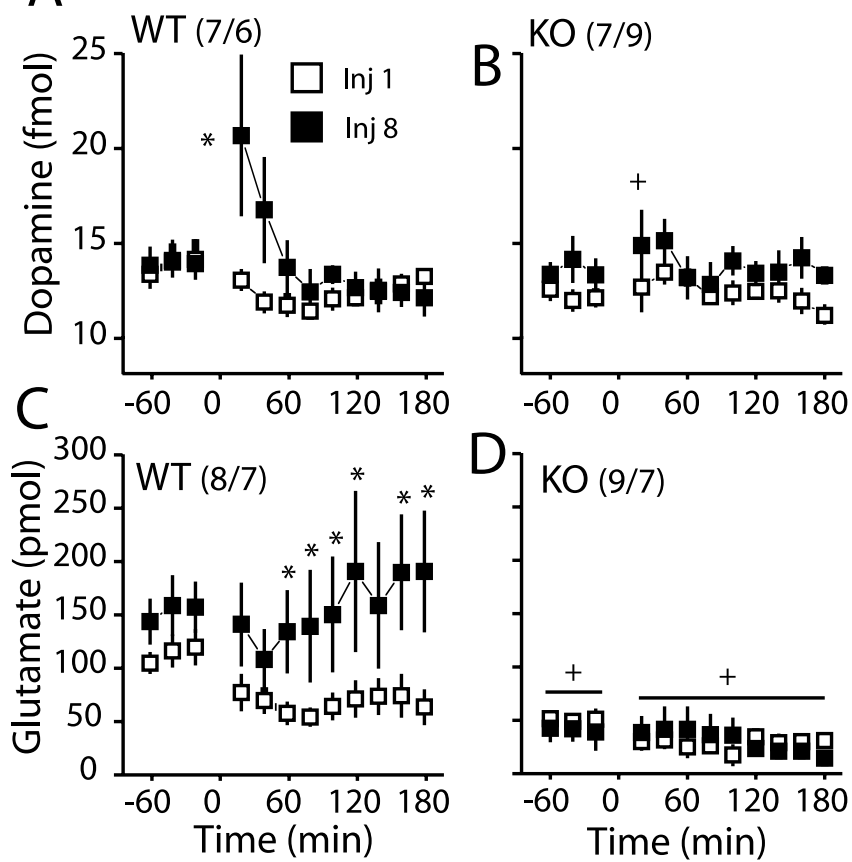

D

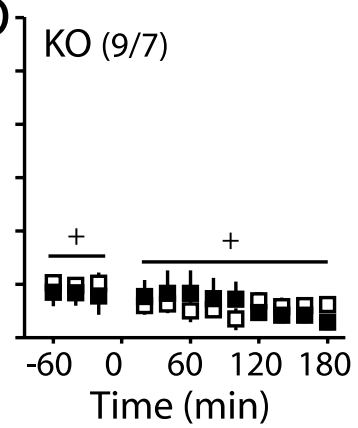

Figure 3. Homer2 $\mathrm{KO}$ mice do not exhibit neurochemical adaptation with repeated EtOH administration. $\boldsymbol{A}$, The capacity of $3 \mathrm{~g} / \mathrm{kg}$ EtOH to elevate extracellular levels of dopamine in the nucleus accumbens was facilitated by eight injections of EtOH in WT mice. $\boldsymbol{B}$, Repeated EtOH did not induce a change in extracellular dopamine in $\mathrm{KO}$ animals (genotype $\times$ injection $\times$ time, $\left.F_{(11,275)}=2.31 ; p=0.007\right)$. C, Repeated EtOH augmented the effect of EtOH on extracellular glutamate in WT mice. $\boldsymbol{D}$, No such neurochemical adaptation was observed in $\mathrm{KO}$ animals (genotype $\times$ injection $\times$ time, $\left.F_{(11,297)}=1.59 ; p=0.06\right)$. Data represent the mean $\pm \mathrm{SEM}$ extracellular levels of neurotransmitter per 20 min fraction, and the number of animals is in parentheses. ${ }^{*} p<0.05$ versus injection $1 ;{ }^{+} p<0.05$ versus WT on injection 8 (LSD post hoc tests).

dose of $\mathrm{EtOH}(5 \mathrm{~g} / \mathrm{kg})$. Homer2 $\mathrm{KO}$ mice exhibited a longer latency to regain their righting reflex than did WT mice (Fig. 2C).

\section{Homer2 deletion prevented EtOH-induced neurochemical adaptation in the accumbens}

Genetic variation in vulnerability to high EtOH consumption is associated with an augmented capacity of either acute or repeated EtOH to increase extracellular levels of dopamine (Smith and Weiss, 1999) and glutamate (Selim and Bradberry, 1996). Thus, the effect of acute and repeated EtOH administration $(3 \mathrm{~g} / \mathrm{kg}$ for eight injections) on accumbens extracellular levels of these neurotransmitters were assessed using in vivo microdialysis. As reported previously (Szumlinski et al., 2004), basal extracellular levels of dopamine did not differ between WT and KO mice, whereas basal extracellular levels of glutamate of $\mathrm{KO}$ mice were $\sim 50 \%$ that of WT before both injections 1 and 8 of repeated
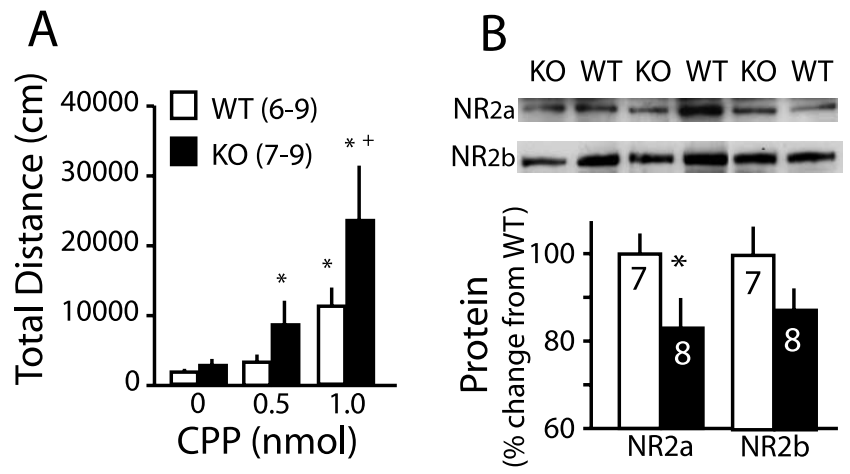

Figure 4. Homer2 KO mice exhibit abnormalities in accumbens NMDA receptor function and plasma membrane expression. $\boldsymbol{A}$, Homer2 KO mice exhibited increased sensitivity to the locomotor-stimulant effects of an intra-accumbens infusion of the competitive NMDA receptor antagonist CPP (genotype effect, $F_{(1,44)}=2.87, p=0.04$; genotype $\times$ dose interaction, $\left.F_{(2,44)}=2.21, p=0.07\right)$. $\boldsymbol{B}$, Reduced membrane-bound NMDA receptor subtypes NR2a $\left(t_{(13)}=2.271 ; p=0.04\right)$ and NR2b $\left(t_{(13)}=1.987 ; p=0.07\right)$ in accumbens of KO mice. Protein data were normalized to percentage change from WT, and all data are shown as mean \pm SEM. The number of animals is indicated in parentheses or in the bars. ${ }^{*} p<0.05$ versus $0 \mathrm{nmol}$ CPP; ${ }^{+} p<0.05$ versus WT (LSD post hoc tests or $t$ tests).

EtOH (Table 1). Compared with injection 1, the capacity of EtOH to elevate extracellular levels of both dopamine and glutamate was enhanced on injection 8 in WT mice (Fig. $3 A, C$ ). In contrast, neither dopamine nor glutamate changed between injection 1 and 8 in $\mathrm{KO}$ mice (Fig. $3 B, D$ ).

\section{Homer2 deletion enhanced sensitivity to intra-accumbens NMDA receptor blockade}

EtOH modulates NMDA channel opening and trafficking (Chandler, 2003), and genetic vulnerability to alcoholism has been associated with a blunting of the perceptual and dysphoric responses to NMDA receptor antagonists (Krystal et al., 2003). The locomotor response to an intra-accumbens microinjection of the competitive NMDA antagonist CPP was used to determine whether the decrease in EtOH-induced behavioral and neurochemical neuroplasticity in Homer2 $\mathrm{KO}$ mice was correspondingly associated with altered responsiveness to NMDA antagonism. CPP elicited a greater increase in locomotor activity in Homer2 $\mathrm{KO}$ mice (Fig. 4A). Because Homer2 regulates the synaptic localization of NMDA receptors during development (Shiraishi et al., 2003), the enhanced responsiveness to NMDA antagonism could result from reduced surface expression of NMDA receptors. The amount of the NR2a subunit in the accumbens membrane fraction was significantly reduced in $\mathrm{KO}$ compared with WT mice, whereas the NR2b subunit showed a trend toward a reduction (Fig. $4 B$ ). In contrast, although mGluR5 binds directly to Homer (Tu et al., 1998), no significant genotypic difference was observed in membrane content of the dimer and mono- 
mer of mGluR5 (dimer WT, $100 \pm 6.6$, $n=8 ; \mathrm{KO}, 90.2 \pm 4.9, n=7$; monomer WT, $100 \pm 7.5, n=8 ; \mathrm{KO}, 104.2 \pm 11.6$, $n=8$ ).

\section{Intra-accumbens AAV-Homer2b infusion eliminated the genotypic differences in EtOH-induced neuroplasticity}

To confirm an active role for accumbens Homer2 expression in the regulation of EtOH-induced neuroplasticity, an AAV carrying either Homer $2 b$ or GFP control cDNA was infused into the accumbens of $\mathrm{WT}$ and Homer2 $\mathrm{KO}$ mice. Homer $2 b$ was HA tagged, and AAV transfection was verified by immunostaining (Fig. $5 a$ ). Cellular transfection was restricted to an area of $\sim 1 \mathrm{~mm}$ around the injection site in the nucleus accumbens, and protein expression was localized to both processes and soma (Fig. $5 a^{\prime}, a^{\prime \prime}$ ). Starting 3 weeks after AAV infusion, mice were assessed for EtOH-induced changes in accumbens neurotransmission ( $3 \mathrm{~g} / \mathrm{kg}$ for eight injections) or tested for $\mathrm{EtOH}$-induced place conditioning ( $3 \mathrm{~g} / \mathrm{kg}$ for eight injections) and then evaluated for EtOH preference and consumption in a $24 \mathrm{~h}$ ad libitum access four-bottle choice procedure $(0,3,6$, and $12 \% \mathrm{EtOH})$. Intra-accumbens AAVHomer $2 b$ infusion enhanced $\mathrm{EtOH}$ preference in both WT and $\mathrm{KO}$ mice, as revealed by an upward shift in the EtOH dosepreference curve at low EtOH concentrations (Fig. 5b) and a reduction in the cumulative preference for water (Fig. 5C). Although AAV-Homer $2 b$ infusion did not influence total EtOH intake by WT mice, it reversed the genotypic difference over the $24 \mathrm{~h}$ test period (Fig. 5d). AAVHomer $2 b$ infusion also reversed the genotypic difference in the expression of $\mathrm{EtOH}$-induced place conditioning, as revealed by a significant difference in the expression of place conditioning between AAV-GFP WT and KO mice but not between AAV-Homer $2 b$ WT and $\mathrm{KO}$ mice (Fig. 5e). A similar effect of AAV-Homer $2 b$ infusion was observed for the change in locomotion produced by repeated $\mathrm{EtOH}$ administration between the first and eighth EtOH conditioning session (Fig. 5f).

The EtOH preference data for WT mice indicated a significant but modest shift to the left in EtOH preference by AAV-Homer $2 b$ infusion (Fig. 5b). To ascertain whether or not a similar effect of AAV-Homer $2 b$ infusion would be observed in mice with a genetic propensity to consume high amounts of $\mathrm{EtOH}$, we examined the effects of AAV infusion on $\mathrm{EtOH}$ preference and intake in $\mathrm{B} 6$ mice. As illustrated in Figure 6A, AAV-Homer $2 b$ infusion into the accumbens of B6 mice produced a marked shift to the left in the EtOH preference function, as well as an enhancement in the preference for $18 \% \mathrm{EtOH}$. In a manner akin to that observed for
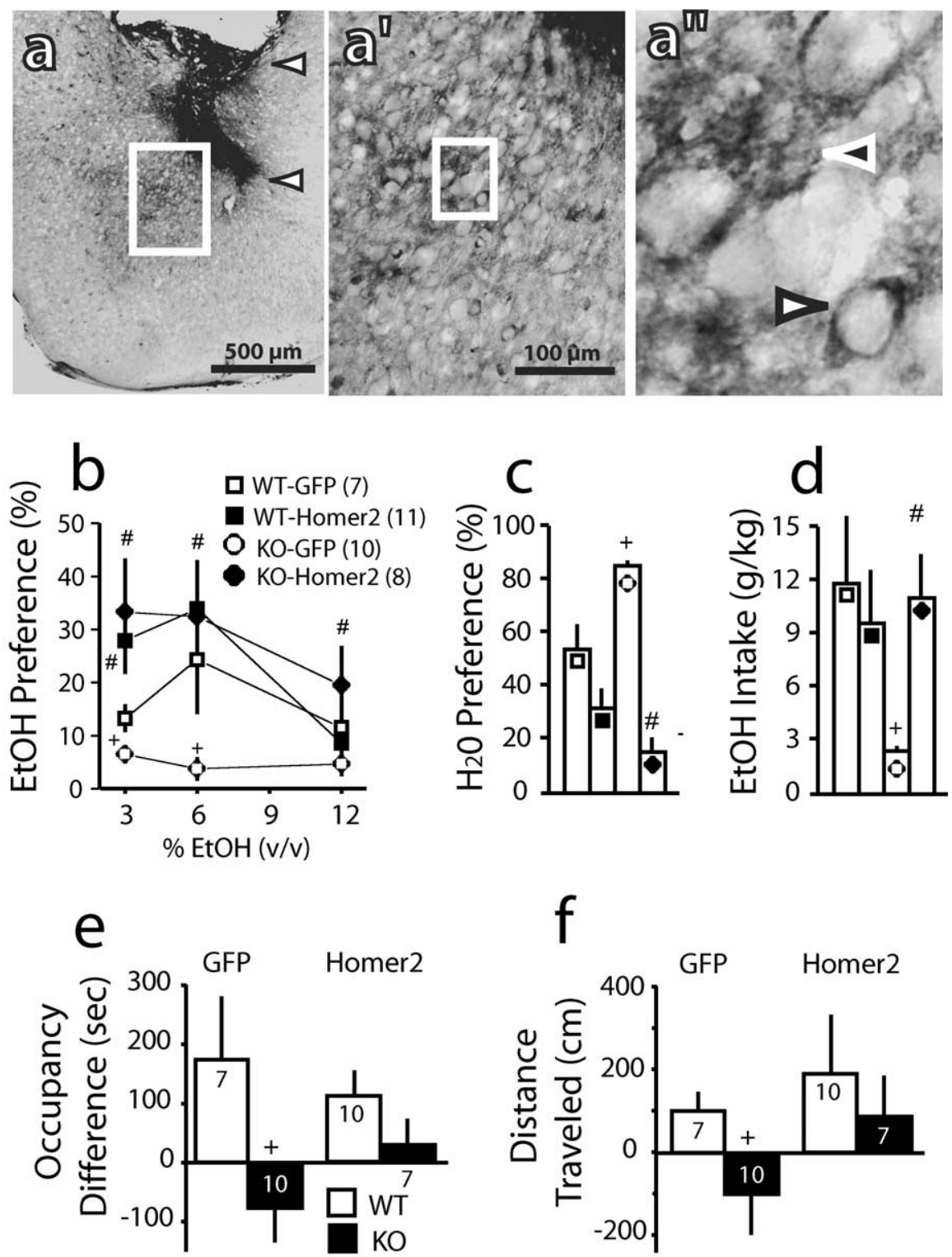

Figure 5. AAV-Homer2b reverses the genotypic differences in EtOH behavior. $\boldsymbol{a}-\boldsymbol{a}^{\prime \prime}$, Representative micrographs of immunostaining for AAV-transfected HA-tagged Homer2b in accumbens. Arrowheads indicate glial scar from injection (a) and fiber (black fill) or soma (white fill) labeling $\left(\boldsymbol{a}^{\prime \prime}\right)$. $\boldsymbol{b}$, AAV-Homer2b infusion shifted EtOH (EtOH) preference to the left in both WT and KO mice (genotype $\times$ dose $\times$ AAV interaction, $\left.F_{(3,96)}=4.38 ; p=0.006\right)$. c, AAV-Homer $2 \mathrm{~b}$ infusion reduced the preference for water in KO mice (genotype $\times A A V, F_{(1,35)}=9.95 ; p=0.003$ ). $\boldsymbol{d}$, AAV-Homer2b infusion restored EtOH intake (on a gram per kilogram body weight basis) in $\mathrm{KO}$ mice to the level exhibited by WT animals (genotype $\times A A V, F_{(1,35)}=7.38 ; p=0.011$ ). $\boldsymbol{e}$, Whereas planned comparisons revealed genotypic differences in the capacity of eight pairings of $3 \mathrm{~g} / \mathrm{kg}$ EtOH to elicit place conditioning were observed in between AAV-GFP WT and K0 mice $\left(F_{(1,16)}=5.20 ; p=0.04\right)$, this difference was not apparent between AAV-Homer2b WT and $\mathrm{KO}$ animals $\left(F_{(1,16)}=1.75 ; p=0.21\right)$. $f$, Planned comparisons also revealed that AAV-Homer2b reversed the genotypic difference in locomotor adaptation produced by eight injections of $3 \mathrm{~g} / \mathrm{kg} \mathrm{EtOH}$ (for GFP, $F_{(1,16)}=10.41, p=0.006$; for Homer $\left.2 b, F_{(1,16)}=0.57, p=0.46\right)$. Data in $\boldsymbol{b}-f$ represent the mean \pm SEM of the number of animals indicated. ${ }^{+} p<0.05$ versus respective WT; $p<0.05$ versus respective AAV-GFP.

WT mice (Fig. $5 d$ ), AAV-Homer $2 b$ infusion did not influence the intake of any of the EtOH concentrations tested (Fig. 6B). Thus, AAV-Homer $2 b$ infusion increases preference for $\mathrm{EtOH}$ in both moderate and high consuming mice, without altering total $\mathrm{EtOH}$ intake.

Intra-accumbens AAV-Homer $2 b$ infusion elevated accumbens glutamate content in both WT and KO mice but did not influence basal extracellular levels of dopamine (Table 1). Similar to nontransfected WT mice (Fig. 3), repeated EtOH injections increased accumbens extracellular levels of glutamate (Fig. 7A) 
and dopamine (Fig. 7E) in AAV-GFP WT mice. Also akin to the data in Figure 3, AAV-GFP-transfected KO mice showed no augmentation in glutamate or dopamine after repeated EtOH (Fig. $7 C, G)$. Although AAV-Homer $2 b$ transfection of WT mice did not alter the sensitization of glutamate produced by repeated $\mathrm{EtOH}$ (Fig. $7 B$ ), the sensitized increase in extracellular dopamine was augmented by AAV-Homer2b transfection (Fig. 7F). Restoring Homer2b with intra-accumbens AAV-Homer $2 b$ enabled the enhanced dopamine and glutamate responses to EtOH after repeated treatment in $\mathrm{KO}$ mice (Fig. $7 \mathrm{D}, \mathrm{H}$ ).

\section{Discussion}

The present report provides in vivo validation of the involvement of Homer proteins in neuroplasticity by showing that Homer2
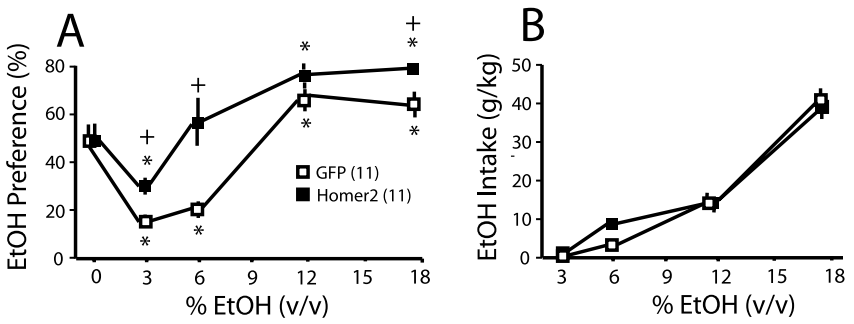

Figure 6. AAV-Homer2b augments EtOH preference in EtOH-preferring $\mathrm{B} 6$ mice. $\boldsymbol{A}$, Intraaccumbens infusion of AAV-Homer2b shifted the preference of $\mathrm{B} 6$ mice toward lower EtOH concentrations and enhanced preference for higher EtOH concentrations (AAV $\times$ dose, $\left.F_{(4,80)}=4.71 ; p=0.002\right)$. $B$, Despite the shift in preference, AAV-Homer2b infusion did not alter the average amount of EtOH consumed at any concentration tested (AAV $\times$ dose, $F_{(3,60)}=$ $1.13 ; p=0.35]$. ${ }^{*} p<0.05$ versus $0 \% \mathrm{EtOH} ;+p<0.05$ versus AAV-GFP.
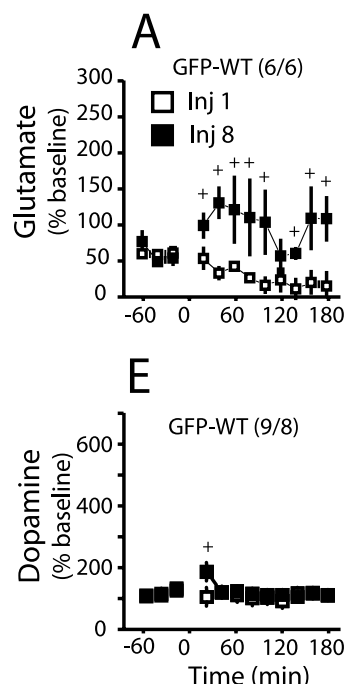

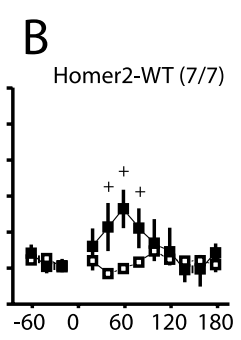

$\mathrm{F}$

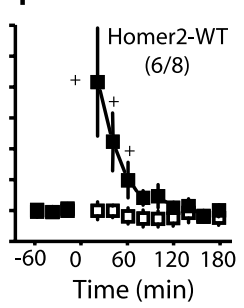

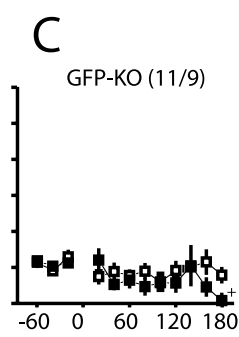

G

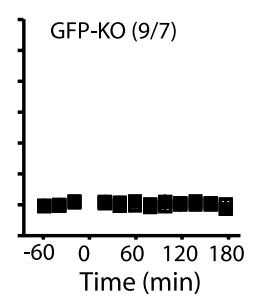

gene deletion impairs the development of behavioral and neurochemical plasticity to repeated EtOH administration. This complements previous in vitro anatomical and electrophysiological studies showing that Homer proteins regulate synaptic plasticity and remodeling (Xiao et al., 2000; de Bartolomeis and Iasevoli, 2003). Indeed, in vitro studies show that Homer proteins cluster EVH1-bound proteins in the PSD, including NMDA receptorShank scaffolding complexes (Tu et al., 1999), and the present study demonstrated that Homer2 deletion decreased the plasma membrane content of NMDA receptor subunits in the accumbens. The nucleus accumbens is a critical site for neuroplasticity in dopamine and glutamate transmission underlying the development of addiction (Nestler, 2001; Chandler, 2003; Kalivas et al., 2005). The fact that Homer 2 deletion induced parallel deficits in the capacity of repeated $\mathrm{EtOH}$ to induce place preference and motor sensitization and to elicit sensitization in accumbens glutamate and dopamine transmission supports the link between these behaviors and accumbens neurotransmission. Moreover, Homer proteins in the accumbens were shown to be critical in mediating this linkage because intra-accumbens AAV-Homer $2 b$ infusion reversed the genotypic differences in $\mathrm{EtOH}$-induced behavioral and neurochemical plasticity.

\section{Homer2 regulates EtOH effects on dopamine and glutamate transmission}

Imaging studies in EtOH-dependent humans show an association between the propensity to consume large amounts of $\mathrm{EtOH}$ and $\mathrm{EtOH}$-induced increases in metabolic activity in the accumbens and mesocortical structures supplying glutamatergic inner-

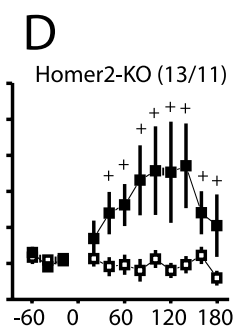

$\mathrm{H}$

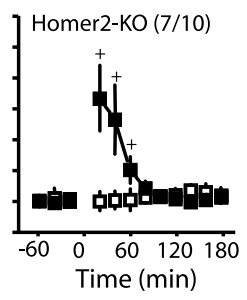

Figure 7. AAV-Homer2b reverses the genotypic difference in EtOH-induced adaptations in extracellular glutamate and dopamine. Intra-accumbens infusion of AAV-Homer2b reversed the genotypic difference in the capacity of eight injections of $3 \mathrm{~g} / \mathrm{kg}$ EtOH to elevate extracellular accumbens levels of glutamate (genotype $\times$ AAV $\times$ injection number $\times$ time, $F_{(11,495)}=4.99 ; p<$ 0.0001) and dopamine (AAV $\times$ injection number $\times$ time, $\left.F_{(11,616)}=6.91 ; p<0.0001\right)$. $\boldsymbol{A}$, Repeated Et0H elevated extracellular levels of glutamate in AAV-GFP WT mice (injection $\times$ time, $\left.F_{(11,99)}=3.45 ; p=0.04\right)$. $\boldsymbol{B}$, A similar effect of repeated EtOH was observed in AAV-Homer2b WT mice (injection $\times$ time, $F_{(11,96)}=3.69 ; p<0.0001$ ). $C$, Repeated EtOH produced a modest reduction in extracellular glutamate in AAV-GFP K0 mice (injection $\times$ time, $F_{(11,176)}=3.00 ; p=0.001$ ). $\boldsymbol{D}$, The glutamate response to repeated EtOH in AAV-Homer2b KO was similar to that observed in WT mice (injection $\times$ time, $F_{(11,154)}=3.83 ; p<$ 0.0001). $\boldsymbol{E}$, Repeated EtOH increases extracellular levels of dopamine in AAV-GFPWT mice (injection $\times$ time, $F_{(11,165)}=2.04 ; p=$ 0.03). $\boldsymbol{F}$, This effect was enhanced in AAV-Homer2b WT mice (injection $\times$ time, $\left.F_{(11,132)}=3.44 ; p<0.0001\right)$. $\boldsymbol{G}$, Repeated EtOH did not affect extracellular dopamine in AAV-GFP KO mice (injection $\times$ time, $F_{(11,154)}=0.45 ; p=0.93$ ). $\boldsymbol{H}$, The dopamine response to repeated EtOH in $\mathrm{AAV}$-Homer2b KO mice was similar to that observed in AAV-Homer2b WT mice (injection $X$ time, $F_{(11,165)}=5.06 ; p<0.0001$ ). Data represent the mean \pm SEM percentage change from baseline values (for moles per sample, see Table 1) per 20 min fraction, and the number of animals is in parentheses (injection 1/injection 8 ). ${ }^{+} p<0.05$ versus injection 1 (LSD post hoc tests). vation of the accumbens (Moselhy et al., 2001; Meyerhoff et al., 2004). EtOH elevates accumbens extracellular levels of glutamate in EtOH-drinking Lewis rats but not in low EtOH-drinking Fischer 344 rats (Selim and Bradberry, 1996) and facilitates evoked glutamate release in cortical slices in EtOH-preferring, but not in EtOH-nonpreferring, rats (McBride et al., 1986). Moreover, low-EtOH sensitive rats exhibit an increase in accumbens levels of extracellular glutamate compared with high-EtOH sensitive rats (Dahchour et al., 2000), and EtOH-tolerant rats display less of an EtOH-induced inhibition of accumbens extracellular glutamate compared with EtOH-nontolerant rats (Piepponen et al., 2002). The hyporesponsiveness of accumbens glutamate in rats selectively bred for low EtOH preference and high sensitivity to the motor-impairing effects of EtOH parallels the behavioral and glutamatergic phenotype of Homer2 $\mathrm{KO}$ mice. Although a role for Homer2 in the rat strain distinctions remains to be determined, the restoration of $\mathrm{EtOH}$-induced glutamatergic and behavioral plasticity by AAV-Homer $2 b$-mediated overexpression in the accumbens implicates Homer2 regulation of extracellular glutamate in sensitivity to the psychomotor-impairing effects of EtOH, a major predictor of subsequent EtOH consumption (Schuckit and Smith, 2000). 
Microdialysis studies in rats selectively bred for high versus low EtOH preference/consumption show an increased capacity of acute or repeated $\mathrm{EtOH}$ to elevate accumbens extracellular levels of dopamine in high consuming lines (McBride and $\mathrm{Li}$, 1998). Given the role for accumbens dopamine transmission in mediating the rewarding effects of EtOH (Koob et al., 1998; Gonzales et al., 2004), the EtOH-avoiding phenotype of Homer2 $\mathrm{KO}$ mice may result from a failure of repeated $\mathrm{EtOH}$ to induce dopaminergic adaptations. The lack of EtOH-induced dopamine plasticity in the accumbens of Homer $2 \mathrm{KO}$ mice is not likely a direct effect of gene deletion on basal dopamine transmission or dopamine transporter function because basal extracellular levels of dopamine and the rise in dopamine produced by blocking the dopamine transporter is similar between WT and KO mice (Szumlinski et al., 2004). Interestingly, Homer $2 b$ transfection not only restored the sensitization of extracellular dopamine by repeated EtOH administration in Homer $2 \mathrm{KO}$ mice but also accentuated the EtOH-induced increase in dopamine in WT mice. Because Homer proteins are traditionally studied in relation to glutamate transmission, mechanisms underlying the augmentation in extracellular dopamine after $A A V$-Homer $2 b$ transfection are unclear. It is possible that $A A V$-Homer $2 b$ transfection of GABAergic accumbens spiny cells projecting to the ventral tegmental area may have reduced inhibitory feedback regulation of dopamine neurons. Supporting this possibility, EtOH-induced increases in accumbens dopamine arise in part from actions on GABA transmission in the ventral tegmental area (Gallegoa et al., 1999; McBride et al., 1999; Melis et al., 2002).

\section{Homer, NMDA receptors, and EtOH sensitivity}

Homers regulate the anchoring and synaptic localization of NMDA receptors by interacting with the Shank-PSD-95-GKAP (for guanylate kinase domain-associated protein) complex of PSD proteins (Naisbitt et al., 1999; Shiraishi et al., 2003). The NR2 subunits of the NMDA receptor contain PDZ (for PSD-95/ Discs large/zona occludens-1)-binding domains that link NMDA receptors to the Homer-Shank-PSD-95-GKAP complex (Naisbitt et al., 1999). Although Homer2 deletion does not alter the total protein content of NR2a or NR2b in the accumbens (Szumlinski et al., 2004), the plasma membrane localization of NR2a was reduced. Reduced plasma membrane-bound NR2a in the accumbens of Homer2 $\mathrm{KO}$ mice is consistent with decreased in vitro cell surface NMDA receptors after either mutagenesis of Homer isoforms or overexpression of the dominant-negative immediate early gene product Homerla (Sala et al., 2001, 2003).

EtOH antagonizes NMDA channel function, and the NR2 subunit is critical for this action (Lovinger et al., 1989; Woodward, 2000). Inhibition of NMDA by EtOH contributes to the intoxicating and subjective effects of higher EtOH doses (Chandler, 2003; Krystal et al., 2003). Moreover, blunted responsiveness to NMDA antagonists is associated with vulnerability to EtOH addiction (Krystal et al., 2003). Consistent with this clinical association, the reduced EtOH preference in Homer2 $\mathrm{KO}$ mice was accompanied by increased sensitivity to the sedative and aversive properties of EtOH and to the psychomotor-activating effects of NMDA receptor blockade. Although more experiments are necessary, reduced surface expression of NR2a to the membrane in Homer2 $\mathrm{KO}$ mice is consistent with greater sensitivity to NMDA receptor antagonists. Thus, Homer-mediated anchoring of NMDA receptors may gate behavioral sensitivity to the acute effects of EtOH, which is negatively associated with subsequent EtOH consumption (Schuckit and Smith, 2000; Krystal et al., 2003). Similarly, Homer regulation of NMDA receptor anchor- ing may contribute to the enduring changes in dopamine and glutamate transmission produced by repeated EtOH administration. Thus, although additional study is necessary to conclude involvement of NMDA receptors in the Homer2 KO phenotype, the present study points to Homer2-mediated organization of the NMDA receptor scaffold as a possible regulator of acute sensitivity to $\mathrm{EtOH}$ and vulnerability to $\mathrm{EtOH}$-induced neuroplasticity.

\section{References}

Backstrom P, Bachteler D, Koch S, Hyytia P, Spanagel R (2004) mGluR5 antagonist MPEP reduces ethanol-seeking and relapse behavior. Neuropsychopharmacology 29:921-928.

Chandler LJ (2003) Alcohol and brain plasticity: receptors and molecular networks of the postsynaptic density as targets of alcohol. Pharmacol Ther 99:311-326.

Dahchour A, Hoffman A, Deitrich R, De Witte P (2000) Effects of alcohol on extracellular amino acid levels in high- and low-alcohol sensitive rats: a microdialysis study. Alcohol Alcohol 35:548-553.

de Bartolomeis A, Iasevoli F (2003) The Homer family and the signal transduction system at glutamatergic postsynaptic density: potential role in behavior and pharmacotherapy. Psychopharmacol Bull 37:51-83.

Gallegoa RA, Lee R-S, Criado JR, Henriksen SJ, Steffenssen SC (1999) Adaptive response of $\gamma$-aminybutyric acid neurons in the ventral tegmental area to chronic alcohol. J Pharmacol Exp Ther 291:1045-1052.

Gonzales RA, Job MO, Doyon WM (2004) The role of mesolimbic dopamine in the development and maintenance of alcohol reinforcement. Pharmacol Ther 103:121-146.

Kalivas PW, Volkow N, Seamans J (2005) Unmanageable motivation in addiction: a pathology in prefrontal-accumbens glutamate transmission. Neuron 45:647-650.

Koob GF, Roberts AJ, Schulteis G, Parsons LH, Heyser CJ, Hyytia P, MerloPich E, Weiss F (1998) Neurocircuitry targets in alcohol reward and dependence. Alcohol Clin Exp Res 22:3-9.

Krystal JH, Petrakis IL, Mason G, Trevisan, D’Souza DC (2003) N-methylD-aspartate glutamate receptors and alcoholism: reward, dependence, treatment and vulnerability. Pharmacol Ther 99:79-94.

Lovinger DM, White G, Weight FF (1989) Alcohol inhibits NMDAactivated ion current in hippocampal neurons. Science 243:1721-1724.

McBride WJ, Li T-K (1998) Animal models of alcoholism: neurobiology of high alcohol-drinking behavior in rodents. Crit Rev Neurobiol 112:339-369.

McBride WJ, Murphy JM, Lumeng L, Li T-K (1986) Effects of alcohol on monoamine and amino acid release from cerebral cortex slices of the alcohol-preferring P line of rats. Alcohol Clin Exp Res 10:205-208.

McBride WJ, Murphy JM, Ikemoto S (1999) Localization of brain reinforcement mechanisms: intracranial self-administration and intracranial place conditioning studies. Behav Brain Res 101:129-152.

Melis M, Camarini R, Ungless MA, Bonci A (2002) Long-lasting potentiation of GABAergic synapses in dopamine neurons after a single in vivo alcohol exposure. J Neurosci 22:2074-2082.

Meyerhoff DJ, Blumenfeld R, Truran D, Lindgren J, Flenniken D, Cardenas V, Chao LL, Rothlind J, Studholme C, Weiner MW (2004) Effects of heavy drinking, binge drinking, and family history of alcoholism on regional brain metabolites. Alcohol Clin Exp Res 28:650-661.

Middaugh LD, Frackleton WT, Boggan WO, Onofrio A, Shepherd CL (1992) Gender differences in the effects of alcohol on C57BL/6 mice. Alcohol 9:257-260.

Moselhy HF, Georgiou G, Khan A (2001) Frontal lobe changes in alcoholism: a review of the literature. Alcohol Alcohol 36:357-368.

Naisbitt S, Kim E, Tu JC, Xiao B, Sala C, Valtschanoff J, Weinberg RJ, Worley PF, Sheng M (1999) Shank, a novel family of postsynaptic density proteins that binds to the NMDA receptor/PSD-95/GKAP complex and cortactin. Neuron 23:569-582.

Nestler E (2001) Molecular basis of long-term plasticity underlying addiction. Nature Rev 2:119-128.

Nocjar C, Middaugh LD, Tavernetti M (1999) Alcohol consumption and place-preference conditioning in the alcohol-preferring C57BL/6 mouse: relationship with motor activity patterns. Alcohol Clin Exp Res 23:683-692.

Piepponen TP, Kiianmaa K, Ahtee L (2002) Effects of alcohol on the accumbal output of dopamine, GABA and glutamate in alcohol-tolerant and alcohol-nontolerant rats. Pharmacol Biochem Behav 74:21-30. 
Rong R, Ahn JY, Huang H, Nagata E, Kalman D, Kapp JA, Tu J, Worley PF, Snyder SH, Ye K (2003) PI3 kinase enhancer-Homer complex couples mGluRI to PI3 kinase, preventing neuronal apoptosis. Nat Neurosci 6:1153-1161

Sala C, Piech V, Wilson NR, Passafaro M, Liu G, Sheng M (2001) Regulation of dendritic spine morphology and synaptic function by Shank and Homer. Neuron 31:115-130.

Sala C, Futai K, Yamamoto K, Worley PF, Hayashi Y, Sheng M (2003) Inhibition of dendritic spine morphogenesis and synaptic transmission by activity-inducible protein Homerla. J Neurosci 23:6327-6337.

Schuckit MA, Smith TL (2000) The relationships of a family history of alcohol dependence, a low level of response to alcohol and six domains of life functioning to the development of alcohol use disorders. J Stud Alcohol 61:827-835.

Selim M, Bradberry CW (1996) Effect of alcohol on extracellular 5-HT and glutamate in the nucleus accumbens and prefrontal cortex: comparison between the Lewis and Fischer 344 rat strains. Brain Res 716:157-164.

Shiraishi Y, Mizutani A, Mikoshiba K, Furuichi T (2003) Coincidence in dendritic clustering and synaptic targeting of homer proteins and NMDA receptor complex proteins NR2B and PSD95 during development of cultured hippocampal neurons. Mol Cell Neurosci 22:188-201.

Smith AD, Weiss F (1999) Alcohol exposure differentially alters central monoamine neurotransmission in alcohol-preferring versus -nonpreferring rats. J Pharmacol Exp Ther 288:1223-1228.

Szumlinski KK, Dehoff MH, Kang SH, Frys KA, Lominac KD, Rohrer J, Griffin III W, Klugmann M, Toda S, Champtiaux NP, Berry T, Shealy S,
During MT, Middaugh LD, Worley PF, Kalivas PW (2004) Homer proteins regulate vulnerability to cocaine. Neuron 43:401-413.

Szumlinski KK, Lominac KD, Kleschen M, Oleson EB, Dehoff M, Schwartz M, Seeberg P, Worley PF, Kalivas PW (2005) Behavioural and neurochemical phenotyping of Homer1 mutant mice: possible implications for schizophrenia. Genes Brain Behav, in press.

Toda S, Alguacil LF, Kalivas PW (2003) Repeated cocaine administration changes the function and subcellular distribution of adenosine A1 receptor in rat nucleus accumbens. J Neurochem 87:1478-1484.

Tu JC, Xiao B, Yuan JP, Lanahan AA, Leoffert K, Li M, Linden DJ, Worley PF (1998) Homer binds a novel proline-rich motif and links group 1 metabotropic glutamate receptors with IP3 receptors. Neuron 21:717-726.

Tu JC, Xiao B, Naisbitt S, Yuan JP, Petralia RS, Brakeman P, Doan A, Aakalu VK, Lanahan AA, Sheng M, Worley PF (1999) Coupling of mGluR/ Homer and PSD-95 complexes by the Shank family of postsynaptic density proteins. Neuron 23:583-592.

Woodward JJ (2000) Alcohol and NMDA receptor signaling. Crit Rev Neurobiol 14:69-89.

Xiao B, Tu JC, Worley PF (2000) Homer: a link between neural activity and glutamate receptor function. Curr Opin Neurobiol 10:370-374.

Yuan JP, Kiselyov K, Shin DM, Chen J, Shcheynikov N, Kang SH, Dehoff MH, Schwarz MK, Seeburg PH, Muallem S, Worley PF (2003) Homer binds TRPC family channels and is required for gating of TRPC1 by IP3 receptors. Cell 114:777-789. 